\title{
Umbilical cord trace elements and minerals and risk of early childhood wheezing and eczema
}

\author{
S.O. Shaheen*, R.B. Newson*, A.J. Henderson", P.M. Emmett", A. Sherriff*, M. Cooke ${ }^{\star}$ and the \\ ALSPAC Study Team
}

Umbilical cord trace elements and minerals and risk of early childhood wheezing and eczema. S.O. Shaheen, R. B. Newson, A.J. Henderson, P.M. Emmett, A. Sherriff, M. Cooke and the ALSPAC Study Team. (C) ERS Journals Ltd 2004.

ABSTRACT: It has been suggested that foetal nutrition might influence the inception of wheezing and atopic disorders in childhood but specific nutrients have not been implicated.

In the Avon Longitudinal Study of Parents and Children umbilical cord samples were assayed for trace elements and minerals, and mothers were asked about wheezing and eczema in their children. Associations of cord concentrations of selenium, zinc, copper, manganese, magnesium, iron, lead and mercury with wheezing at 30-42 months, with wheezing patterns defined by the presence or absence of transient infant, later onset or persistent wheezing at $0-6$ months and 30-42 months, respectively $(n=2,044)$, and with eczema at $18-30$ months $(n=2,173)$, were analysed.

Cord selenium was negatively associated with persistent wheeze (adjusted odds ratio (OR) per doubling concentration: 0.67 ). Cord iron was negatively associated with later onset wheeze (OR: 0.86) and with eczema (OR: 0.90). Children with high cord concentrations of selenium and iron were less likely than those with low concentrations to wheeze transiently in infancy.

The level of foetal exposure to selenium and iron may possibly influence the risk of wheezing and eczema in early childhood although, in view of the multiple analyses carried out, it is possible that the main findings occurred by chance.

Eur Respir J 2004; 24: 292-297.
*Dept of Public Health Sciences, Guy's, King's and St Thomas' School of Medicine, King's College, "Centre for Chemical Sciences, Royal Holloway, University of London, London and ${ }^{\#}$ Unit of Paediatric and Perinatal Epidemiology, Institute of Child Health, University of Bristol, Bristol, UK.

Correspondence: S.O. Shaheen, Dept of Public Health Sciences, Capital House, 42 Weston

Street, London SE1 3QD, UK.

Fax: 44 2078486605/6620

E-mail: seif.shaheen@kcl.ac.uk

Keywords: Birth cohort, eczema, prenatal/foetal nutrition, trace elements/minerals, wheezing

Received: October 212003

Accepted after revision: March 152004

This study was funded by the UK Medical Research Council. S.O. Shaheen and R.B. Newson were funded by the UK Dept of Health. Core funding for the long-term followup of the cohort came from the Medical Research Council, the Wellcome Trust, the UK Dept of Health, the Dept of the Environment, Dept for Education and Employment, the National Institutes of Health, and a variety of medical research charities and commercial sponsors.
Associations between anthropometry at birth and wheezing, asthma, eczema and raised Immunoglobulin (Ig)E [1-6] have led to conjecture that rates of foetal growth, and by implication foetal nutrition, might influence the inception of these conditions through "programming" of the foetal lung and immune development [7]. Whilst little is known about which specific nutrients might be involved, the antioxidant trace element selenium is of particular interest because it is thought to play an important role in lung development in animals [8]. Indirect evidence that prenatal exposure to antioxidants might influence the development of atopy comes from the observation that placental calcification, thought to be a marker of low antioxidant status in pregnancy [9], was associated with higher cord $\operatorname{IgE}$ [10]. Also, it has been suggested that zinc deficiency may promote T-helper (Th) type 2 cytokine responses [11]. In contrast, evidence in animals suggests that high exposure to the heavy metals lead and mercury promotes Th2 cytokine responses in vivo [12], and that high lead exposure in utero causes persistent elevation of IgE in the offspring [13].

Therefore, the current authors postulated that a high foetal exposure to the antioxidant trace elements (selenium, zinc, copper and manganese) might decrease the risk of wheezing and eczema in early childhood, and that high foetal exposure to lead and mercury might increase the risk of these conditions. The present authors speculated that a low foetal exposure to iron might play a role in aetiology, as this causes impaired foetal growth in animals [14], and that a low foetal exposure to magnesium might be a risk factor for wheezing, in view of an association later in life between dietary intake and bronchial hyperresponsiveness (BHR) [15].

The present study explored these hypotheses in a population-based birth cohort, using umbilical cord concentrations of antioxidant trace elements, minerals and heavy metals as biomarkers of foetal exposure.

\section{Methods}

The Avon Longitudinal Study of Parents and Children (ALSPAC) $[16,17]$ is a prospective study of 14,541 pregnancies that resulted in 14,062 live births, of whom 13,971 survived to $1 \mathrm{yr}$. Females were enrolled as early in pregnancy as possible, on the basis of an expected date of delivery between April 1, 1991 and December 31, 1992, and place of residence within the three Bristol-based health districts of the former county of Avon, UK. It was estimated, on the basis of actual deliveries between these dates, that $85-90 \%$ of eligible pregnant women were enrolled. ALSPAC is a multi-purpose study of child health and development, 
which is closely monitored by its own Ethics and Law Committee and by the four local research ethics committees.

\section{Measurement of trace elements and minerals in umbilical cord}

At delivery, umbilical cord samples were taken by the midwife from $\sim 11,500$ births (excluding multiple births and births at peripheral hospitals in Avon) and stored in containers at $-20^{\circ} \mathrm{C}$. Of these, an estimated 9,000 could be linked to mothers who had consented to the analysis of biological samples. As part of a project primarily studying foetal exposure to cadmium and mercury, 2,973 cord samples were analysed for at least one of the elements listed below at Sheffield Hallam University in 1995 (further samples could not be analysed because of lack of funding). This work was carried out long before the authors' hypothesis was conceived. Prior to analysis, $1-\mathrm{cm}$ samples were washed with distilled water to remove cord blood, weighed, digested by closed system microwave digestion using nitric acid and hydrogen peroxide, and made up to $10 \mathrm{~mL}$. In phase 1 the majority of samples $(n=2,005)$ were assayed for up to 13 elements, including magnesium, manganese, iron, copper and zinc, using inductively coupled plasma-optical emission spectrometry (ICP-OES) (separate analyses were carried out for elements present in relatively high concentration e.g. iron, and those present in low concentration e.g. cadmium). Selenium and mercury were assayed using atomic fluorescence techniques (hydride generation for selenium, cold vapour for mercury). However, the last 911 samples were assayed for these elements plus lead, using inductively coupled plasmamass spectrometry (ICP-MS) (phase 2), which was more sensitive than ICP-OES but had not been available for the earlier samples. Element concentrations were measured as $\mathrm{ng} \cdot 10 \mathrm{~mL}^{-1}$ digest and divided by the cord wet weight to give $\mathrm{ng} \cdot \mathrm{g}^{-1}$ of cord and hence parts per billion (ppb). Quality control procedures used bovine liver as a standard reference material to check that each assay method was producing consistent and reliable data over time.

Statistical analyses in the present study were restricted to children for whom at least one of the eight trace elements and minerals of interest had been measured, namely, selenium, zinc, copper, manganese, magnesium, iron, lead and mercury. When the geometric means (GM)s of measurement in the two phases were compared, the current study found that they differed substantially for some elements, especially mercury (table 1). Hence, as each cord sample was assayed in one phase only, and no calibration data were available, each assay value in ppb was divided by the GM of all concentrations for that element using the same method, thereby converting assay values measured in the two phases to a common measurement scale of method-GMs. After converting to a common scale, the current study calculated, for each element, the ratio of the 80 th percentile (in method-GMs) to the 20th percentile (in method-GMs) in order to measure the variability and to assist the interpretation of per-doubling odds ratios (OR)s.

\section{Wheezing and eczema}

Information on wheezing in the child at 30-42 months was obtained by asking the mother at 42 months: "In the last 12 months has he/she had any periods when there was wheezing with whistling on his/her chest when he/she breathed?". A similar question at 6 months asked about wheezing since birth, and the information was used from these two time periods to identify children with four mutually exclusive patterns of wheezing, which the present authors have shown to be associated with different risk factors: those who did not wheeze in either period (nonwheezers); those who wheezed before 6 months but not at 30-42 months (transient infant wheezers); those who wheezed at 30-42 months but not before 6 months (later onset wheezers); those who wheezed in both periods (persistent wheezers) [18].

A 12-month prevalence of eczema at 30 months was defined on the basis of a positive response to the question: "Has your child had an itchy dry skin rash in joints and creases of his/her body (e.g. behind the knees, under the arms) since he/she was 18 months old?" [19].

\section{Confounders}

The potential confounding factors listed in table 2 were controlled for in the multivariate analyses, as well as: maternal atopic disease (asthma, eczema and rhinoconjunctivitis); child's head circumference at birth $(<33 \mathrm{~cm}, 33-34.99 \mathrm{~cm}$, 35-36.99 cm, $>37 \mathrm{~cm}$ or unknown); child's crown-heel length at birth $(<48 \mathrm{~cm}, 48-50.99 \mathrm{~cm}, 51-53.99 \mathrm{~cm},>54 \mathrm{~cm}$ or unknown); mother's body-mass index (pre-pregnancy, selfreported weight and height, $\left.\mathrm{kg} \cdot \mathrm{m}^{-2}\right)(<18.5,18.5-24.99$, 25-29.99, $>30$ or unknown); breast feeding in the first 6 months (no, yes or unknown); and day care use in first 6 months (yes, no or unknown). For all elements, except lead, the present study also controlled for the assay instrument (ICP-OES:ICP-MS OR) in the analyses. Controlling additionally for analgesic use and infections in late pregnancy $[20,21]$ did not alter the main findings. The present study excluded from all the main regression analyses a total of 443 children who were in small missing value categories for various confounders.

Table 1.-Descriptive statistics of umbilical cord trace element and mineral concentrations

\begin{tabular}{|c|c|c|c|c|c|c|c|c|c|}
\hline \multirow[t]{2}{*}{ Element } & \multicolumn{2}{|c|}{$\mathrm{n}$} & \multicolumn{2}{|c|}{ Geometric mean ppb } & \multirow[t]{2}{*}{ Phase 2:Phase 1} & \multirow[t]{2}{*}{$95 \% \mathrm{CI}$} & \multicolumn{2}{|c|}{ Percentile method-GMs } & \multirow{2}{*}{$\frac{\text { IPR }}{(80: 20)}$} \\
\hline & Phase 1 & Phase 2 & Phase 1 & Phase 2 & & & 20th & 80th & \\
\hline Selenium & 1881 & 642 & 0.0591 & 0.0657 & 1.11 & $1.07-1.15$ & 0.76 & 1.26 & 1.64 \\
\hline Zinc & 2005 & 911 & 5.7840 & 7.4483 & 1.29 & $1.24-1.33$ & 0.75 & 1.29 & 1.71 \\
\hline Copper & 2005 & 911 & 0.3968 & 0.7069 & 1.78 & $1.71-1.85$ & 0.73 & 1.31 & 1.79 \\
\hline Manganese & 2005 & 822 & 0.0671 & 0.0407 & 0.61 & $0.57-0.64$ & 0.62 & 1.60 & 2.58 \\
\hline Magnesium & 2004 & 911 & 42.2705 & 45.6626 & 1.08 & $1.05-1.11$ & 0.80 & 1.21 & 1.52 \\
\hline Iron & 2005 & 886 & 45.6013 & 46.9678 & 1.03 & $0.96-1.10$ & 0.52 & 1.99 & 3.85 \\
\hline Lead & 0 & 885 & NA & 0.0270 & NA & & 0.55 & 1.87 & 3.40 \\
\hline Mercury & 1755 & 817 & 0.0127 & 0.0018 & 0.15 & $0.14-0.16$ & 0.54 & 1.83 & 3.38 \\
\hline
\end{tabular}

Method-GMs: method geometric means; IPR: interpercentile ratio; NA: not applicable. 
Table 2. - Comparison of children with and without umbilical cord data

\begin{tabular}{|c|c|c|}
\hline & Without data & With data \\
\hline \multicolumn{3}{|l|}{ Sex } \\
\hline $\mathrm{F}$ & 5404 (48.74) & $1386(46.62)$ \\
\hline M & $5683(51.26)$ & $1587(53.38)$ \\
\hline \multicolumn{3}{|l|}{ Mother's age at birth yrs } \\
\hline$<20$ & $544(4.91)$ & $111(3.73)$ \\
\hline $20-24$ & 2194 (19.79) & $505(16.99)$ \\
\hline $25-29$ & 4247 (38.31) & $1190(40.03)$ \\
\hline $30-34$ & 3011 (27.16) & $866(29.13)$ \\
\hline $35+$ & $1091(9.84)$ & $301(10.12)$ \\
\hline \multicolumn{3}{|l|}{ Mother's parity } \\
\hline 0 & $4457(40.20)$ & $1310(44.06)$ \\
\hline 1 & $3609(32.55)$ & $914(30.74)$ \\
\hline $2+$ & $2143(19.33)$ & $583(19.61)$ \\
\hline Unknown & $878(7.92)$ & $166(5.58)$ \\
\hline \multicolumn{3}{|c|}{ Gestational age at birth weeks } \\
\hline$<37$ & $719(6.49)$ & $131(4.41)$ \\
\hline $37-40$ & $7321(66.03)$ & $1969(66.23)$ \\
\hline $41+$ & 3047 (27.48) & $873(29.36)$ \\
\hline \multicolumn{3}{|c|}{ Maternal smoking in pregnancy } \\
\hline Not exposed & $4192(37.81)$ & $1275(42.89)$ \\
\hline Passive only & $3395(30.62)$ & $890(29.94)$ \\
\hline 1-9 cigarettes $\cdot$ day $^{-1}$ & 964 (8.69) & $270(9.08)$ \\
\hline $10-19$ cigarettes $\cdot$ day $^{-1}$ & 1296 (11.69) & $310(10.43)$ \\
\hline $20+$ cigarettes $\cdot$ day $^{-1}$ & $663(5.98)$ & $129(4.34)$ \\
\hline Unknown & $577(5.20)$ & 99 (3.33) \\
\hline \multicolumn{3}{|l|}{ Mother's education level } \\
\hline$<\mathrm{O}$ level & 2986 (26.93) & $755(25.40)$ \\
\hline O level only & $3320(29.94)$ & $1004(33.77)$ \\
\hline A level + & 3398 (30.65) & $1002(33.70)$ \\
\hline Unknown & 1383 (12.47) & $212(7.13)$ \\
\hline \multicolumn{3}{|l|}{ Mother's housing tenure } \\
\hline Owned/mortgaged & 7415 (66.88) & $2197(73.90)$ \\
\hline Council rented & $1536(13.85)$ & $337(11.34)$ \\
\hline Noncouncil rented & $947(8.54)$ & $211(7.10)$ \\
\hline Unknown/other & $1189(10.72)$ & $228(7.67)$ \\
\hline \multicolumn{3}{|l|}{ Mother's ethnic origin } \\
\hline White & $9376(84.57)$ & $2677(90.04)$ \\
\hline Non-white & $261(2.35)$ & $63(2.12)$ \\
\hline Unknown & $1450(13.08)$ & $233(7.84)$ \\
\hline \multicolumn{3}{|l|}{ Child's birth weight g } \\
\hline$<2500$ & $692(6.24)$ & $111(3.73)$ \\
\hline 2500-2999 & $1610(14.52)$ & $409(13.76)$ \\
\hline 3000-3499 & 3809 (34.36) & $1124(37.81)$ \\
\hline 3500-3999 & $3476(31.35)$ & $911(30.64)$ \\
\hline $4000+$ & 1343 (12.11) & $395(13.29)$ \\
\hline Unknown & 157 (1.42) & $23(0.77)$ \\
\hline
\end{tabular}

Data are presented as n (\%). F: female; M: male.

\section{Statistical methods}

Logistic regression was used to analyse associations with wheezing at 30-42 months and eczema at 18-30 months, and multinomial logistical regression (with never-wheezers as baseline category) to analyse associations with wheezing patterns using Huber variances throughout [22]. The associations between cord element concentrations (expressed as method-GMs) and outcomes were estimated in two ways, first as ORs per doubling of element concentration (by including $\log _{2}$ concentration as a linear predictor variable in the model), and secondly as ORs across quintiles of concentration, with the bottom quintile as the reference category. As there were five outcomes and eight exposures of interest in the analyses, the number of ORs measured was large. Therefore, the Simes procedure was used, controlling the false discovery rate at 0.05 [23], in an attempt to discover a subset of per-doubling
ORs that could be considered statistically significant, given the multiple statistical tests carried out. The analyses were also stratified by measurement phase, and the resulting 80 adjusted per-doubling ORs, with associated p-values, were entered into the Simes' procedure.

\section{Validation of cord assays as biomarkers of prenatal exposure}

As fish is a major source of mercury, the present authors measured the trend in the eight cord element concentrations, assessed in each phase, with mother's consumption of oily and white fish during late pregnancy (as ascertained by food frequency questionnaire at 32 weeks, across four categories of increasing frequency), using Somers' D, with fish consumption as the predictor variable.

\section{Results}

Table 1 summarises the GM concentrations of elements measured in the two phases in ppb, and the ratios between them. It also shows the 20th and 80th percentile concentrations for each element expressed in method-GMs, together with their interpercentile ratio as a measurement of variability. These ratios compare the bottom of the top quintile with the top of the bottom quintile, and varied from 1.52 for magnesium to 3.85 for iron. Consequently, a ratio of two, corresponding to a per-doubling OR, is an appreciable fraction of the range of each exposure.

The current study examined the distribution of selected maternal and birth characteristics of children included in the main analyses (for whom umbilical cord data were available, $\mathrm{n}=2,973$ ), and of children who were not included (table 2). Those with cord data were born between September 1991 and December 1992, those without between January 1991 and February 1993. The characteristics of the two groups were broadly similar, although those with cord data were less likely to have missing information on maternal characteristics.

When the current authors examined the association between maternal fish consumption in pregnancy and cord concentrations of the eight elements in 2,642 children, fish consumption was found to be a predictor of mercury concentration. This association existed both under the first phase (Somers' $D$, $0.11\left(\mathrm{p}=7.5 \times 10^{-6}\right)$ for oily fish and $0.07(\mathrm{p}=0.0045)$ for white fish) and under the second phase (Somers' D, $0.09(\mathrm{p}=0.0072)$ for oily fish and $0.16(\mathrm{p}=0.000014)$ for white fish).

Of 2,530 children with umbilical cord data and information on confounders, the main analyses of the eight elements of interest were restricted to 2,044 with information on wheezing at 6 months and 30-42 months, and 2,173 with information on eczema at 18-30 months. The prevalence of wheezing at $30-42$ months was $13.9 \%$. Table 3 shows the ORs for wheezing, per doubling of umbilical cord trace element and mineral concentrations. After controlling for potential confounding factors, there were no significant associations, with all confidence intervals (CI) including one and excluding any large effects, such as a doubling or halving of the odds.

The prevalences of transient infant, later onset and persistent wheezing patterns were $13.4 \%, 9.1 \%$ and $4.8 \%$, respectively. Table 4 shows associations with wheezing patterns after controlling for potential confounders. There were no significant linear (per-doubling) associations with transient infant wheeze. However, children with high (top quintile) cord concentrations of selenium and iron were less likely than those with low (bottom quintile) concentrations to wheeze transiently in infancy (adjusted ORs (95\% CI): 0.58 (0.36-0.91); $\mathrm{p}=0.019$, and $0.63(0.40-0.99) ; \mathrm{p}=0.044$, 
Table 3.-Odds ratios (OR)s (per doubling concentration) for wheezing at 30-42 months associated with umbilical cord trace element and mineral concentrations

\begin{tabular}{lccccc}
\hline Element & Unadjusted OR & 95\% CI & p-value & Adjusted OR & 95\% CI \\
\hline Selenium & 0.91 & $0.69-1.20$ & 0.51 & 0.99 & $0.75-1.29$ \\
Zinc & 1.08 & $0.86-1.37$ & 0.51 & 1.16 & $0.93-1.44$ \\
Copper & 0.98 & $0.82-1.17$ & 0.81 & 1.01 & 0.18 \\
Manganese & 0.95 & $0.84-1.08$ & 0.46 & 0.94 & $0.84-1.21$ \\
Magnesium & 1.01 & $0.77-1.33$ & 0.91 & 1.03 & $0.82-1.08$ \\
Iron & 0.90 & $0.80-1.01$ & 0.067 & 0.90 & $0.77-1.36$ \\
Lead & 1.03 & $0.88-1.22$ & 0.69 & 1.05 & $0.80-1.02$ \\
Mercury & 0.97 & $0.87-1.08$ & 0.63 & 0.99 & $0.88-1.25$ \\
\hline
\end{tabular}

\#: per doubling concentration. $\mathrm{n}=2,044$.

Table 4.-Adjusted odds ratios (OR)s (per doubling concentration) for wheezing patterns associated with umbilical cord trace element and mineral concentrations

\begin{tabular}{|c|c|c|c|c|c|c|}
\hline \multirow[t]{2}{*}{ Element } & \multicolumn{2}{|c|}{ Transient infant } & \multicolumn{2}{|c|}{ Later onset } & \multicolumn{2}{|c|}{ Persistent } \\
\hline & OR & $95 \% \mathrm{CI}$ & OR & $95 \% \mathrm{CI}$ & OR & $95 \% \mathrm{CI}$ \\
\hline Selenium & 0.77 & & 1.09 & & 0.67 & $(0.4$ \\
\hline Zinc & 0.92 & $(0.71$ & 1.23 & $(0.97-$ & 0.94 & $(0.67-1.31)$ \\
\hline Copper & 0.95 & (0.79-1.14) & 1.00 & $(0.80$ & 1.00 & $(0.77-1.29)$ \\
\hline Manganese & 0.96 & $(0.82-1.13)$ & 0.92 & $(0.77-1.11)$ & 0.96 & $(0.80-1.15)$ \\
\hline Magnesium & 0.96 & $(0.71-1.30)$ & 1.16 & $(0.83-1.62)$ & 0.72 & $(0.48-1.08)$ \\
\hline Iron & 0.93 & $(0.82-1.06)$ & 0.86 & $(0.75-0.99)$ & 0.95 & $(0.79-1.14)$ \\
\hline Lead & 0.96 & $(0.78-1.19)$ & 0.92 & $(0.77-1.09)$ & 1.33 & $(0.96-1.84)$ \\
\hline Mercury & 1.03 & $(0.93-1.15)$ & 0.98 & $(0.86-1.12)$ & 1.04 & $(0.87-1.25)$ \\
\hline
\end{tabular}

$\mathrm{n}=2,044$.

respectively). Iron was negatively associated with later onset wheeze $(\mathrm{p}=0.042)$, and selenium was negatively associated with persistent wheeze $(\mathrm{p}=0.043)$, although this latter effect was explained predominantly by a large reduction in the OR for those in the top quintile compared with the bottom quintile (OR: 0.31 ( 0.12 to 0.78$)$; $\mathrm{p}=0.013)$.

The prevalence of eczema at $18-30$ months was $28.6 \%$. Table 5 shows the ORs for eczema, per doubling of umbilical cord trace element and mineral concentrations. After controlling for potential confounding factors, iron was negatively associated with eczema $(p=0.016)$. The OR, comparing those in the top quintile for iron with those in the bottom quintile, was $0.71(0.52-0.97)$; $\mathrm{p}=0.029$.

When the Simes procedure was carried out on the adjusted per-doubling ORs in the present study, no significant relations were found. When the analyses were stratified by measurement phase and the Simes procedure used, no ORs proved significant. However, for the three nominally significant adjusted per-doubling ORs in tables 4 and 5, the corresponding phase-stratified ORs were as follows. For selenium and persistent wheeze, the per-doubling OR was $0.51(0.33-0.79$; $\mathrm{p}=0.0028)$ under phase 1 and $1.20(0.57-2.53 ; \mathrm{p}=0.62)$ under phase 2. For iron and later-onset wheeze, the OR was $0.91(0.76-1.09 ; \mathrm{p}=0.32)$ under phase 1 and $0.75(0.60-0.94$; $\mathrm{p}=0.013)$ under phase 2. For iron and eczema, the OR was $0.92(0.83-1.02 ; \mathrm{p}=0.11)$ under phase 1 and $0.92(0.82-1.04$; $\mathrm{p}=0.18$ ) under phase 2 .

\section{Discussion}

In this population-based follow-up study the current authors found some evidence to suggest that umbilical cord concentration of selenium was negatively associated with wheezing, and that cord concentration of iron was negatively associated with wheezing and eczema, in early childhood.

\section{Measurement of exposure}

One of the strengths of this study is the use of umbilical cord tissue as a biomarker of foetal exposure to trace elements and minerals. Prenatal mercury and selenium exposure have been previously assessed in this way [24, 25]. In contrast, maternal dietary intake in pregnancy may be a poor proxy for what the foetus actually receives, because the latter also depends on the extent to which nutrients are absorbed by the mother and transferred across the placenta, as well as foetal demand [26]. Furthermore, estimates of the intake of iron and selenium based on food composition tables may be unreliable $[27,28]$, dietary intake on one occasion leads to misclassification [29], and the mother may derive additional nondietary exposure to these elements.

A potential limitation of the present study is that different instruments were used for the cord assays and no calibration data were available. The present authors addressed this problem by controlling for instrument in the analyses, by converting measurements into common method GM units,

Table 5.-Odds ratios (OR)s (per doubling concentration) for eczema at 18-30 months associated with umbilical cord trace element and mineral concentrations

\begin{tabular}{lccccc}
\hline Element & Unadjusted OR $^{\#}$ & $95 \% \mathrm{CI}$ & p-value & Adjusted OR & 95\% CI \\
\hline Selenium & 0.93 & $(0.77-1.11)$ & 0.42 & 0.91 & $(0.76-1.10)$ \\
Zinc & 1.08 & $(0.93-1.26)$ & 0.30 & 1.10 & $0.94-1.28)$ \\
Copper & 0.98 & $(0.86-1.12)$ & 0.74 & 1.00 & 0.34 \\
Manganese & 1.00 & $(0.91-1.10)$ & 0.98 & 0.99 & $(0.88-1.14)$ \\
Magnesium & 0.99 & $(0.82-1.21)$ & 0.95 & 0.99 & $(0.89-1.10)$ \\
Iron & 0.91 & $(0.84-0.98)$ & 0.017 & 0.90 & 0.90 \\
Lead & 0.97 & $(0.84-1.10)$ & 0.61 & 0.97 & $(0.83-0.98)$ \\
Mercury & 1.03 & $(0.95-1.12)$ & 0.43 & 1.03 & 0.92 \\
\hline
\end{tabular}

\footnotetext{
\#: per doubling concentration. $\mathrm{n}=2173$.
} 
and by stratifying analyses by measurement phase. Maternal fish consumption in pregnancy is the major source of prenatal mercury exposure [30]. Hence, to find, as expected, a strong positive association between maternal fish consumption and method GM cord concentration of mercury provided reassurance that, for this element at least, the assays were providing valid estimates of prenatal exposure, and that the conversion of the presented data to a common scale was satisfactory. Any misclassification of cord element concentrations is likely to be random with respect to wheezing and eczema and would tend to lead to an underestimation of the risk estimates. Hence, associations with selenium and iron may be stronger than was estimated by the present authors, although the present study may have failed to detect significant relations with other elements. When the analyses were stratified, the selenium effect on persistent wheeze appeared stronger under the first measurement phase. However, the confidence intervals for the corresponding phase 2 effect were wide. Reassuringly, the iron effects on later onset wheeze and eczema were in the same direction under both measurement phases.

\section{Noncausal explanations for main findings}

Of all the exposures studied, selenium was of greatest interest a priori. However, in view of the multiple analyses and the p-values, it is possible that some, or all, of the findings in the current study occurred by chance. The population from which the ALSPAC cohort was drawn is broadly representative of the whole of the UK [16, 17], although the relations of cord trace elements and minerals to wheezing and eczema were studied in a subset of the cohort. Whilst the cord samples that were analysed were not chosen in any particular way, and the selection and analyses were carried out blind to the outcome measures, the comparison of maternal characteristics of children with and without cord data suggested that information was more complete for the former group. This probably reflects a higher response rate to questionnaires during pregnancy, a higher follow-up rate after delivery, and hence a greater likelihood of obtaining signed consent for analysis of biological samples. However, for this to have biased the current findings, higher cord levels of selenium and iron would have to have been associated with a higher risk of wheezing and eczema amongst children who were not studied, which seems unlikely.

Confounding seems an improbable explanation for the main findings as the present study controlled for an extensive number of potential confounders in the analyses. However, the present authors cannot exclude the possibility of confounding by prenatal exposure to nutrients not included in these analyses, or by postnatal nutrition. The latter may be particularly relevant to later onset or persistent wheezing and eczema, through influences on postnatal airway development or on atopy, since the latter is thought to result primarily from a failure of maturation of Th1 cytokine responses after birth [31].

\section{Possible causal mechanisms}

Whilst a causal interpretation should be cautious, the current authors speculate that the lower prevalence of transient infant wheeze in children with high cord selenium and iron concentrations may indicate beneficial effects of these elements on foetal airway growth, and that the negative association between cord selenium and persistent wheeze might reflect a protective effect of selenium on the development of BHR. The transient infant wheezing pattern is analogous to the transient early wheezing phenotype described in the study by MARTINEZ et al. [32], which occurs with respiratory infections as a consequence of reduced airway calibre, and which disappears as the airways grow in size. In animals there is some evidence that maternal selenium deficiency during pregnancy leads to impaired lung development in the offspring [8]. Whilst maternal iron deficiency causes foetal growth retardation [14], effects on foetal lung growth do not appear to have been studied.

The relations of cord iron with eczema and later onset wheezing suggest, unexpectedly, that higher exposure to iron in utero may protect against the development of atopy. Effects of iron deficiency in pregnancy on placental production of cytokines have been reported in animals [14], although whether maternal iron status would have any influence on Th1/Th2 responses, given that the immunological milieu at the foeto-maternal interface is normally Th2-skewed [33], is unclear. There is some evidence to suggest that iron deficiency or iron reduction therapy later in life may upregulate $\mathrm{Th} 2$ cytokine responses and downregulate Th1 responses [34, 36]. However, evidence is conflicting [35, 37], and interpretation of associations are further complicated by effects of Th1 and Th2 cytokines on iron metabolism [37, 38].

In contrast to the findings for iron, the present study did not find evidence to suggest that low prenatal exposure to zinc, or high exposure to lead and mercury, promoted the development of atopy. Surprisingly, weak positive associations of zinc with later onset wheezing and eczema were found.

\section{Conclusions}

The main findings of this prospective study suggest that the level of foetal exposure to selenium and iron may possibly influence the risk of wheezing and eczema in early childhood. These links, if causal, have potential implications for primary prevention through nutritional interventions during pregnancy. In the UK, pregnant women have a lower selenium status compared to those in other countries [39], and studies in Oxford and in the ALSPAC cohort have shown that pregnant women are not achieving the reference nutrient intakes of selenium [39] (ALSPAC unpublished data) or iron $[40,41]$. However, given that the observations by the current authors are novel and may be attributable to chance, it would seem premature to undertake a supplementation trial in pregnancy without further supportive data.

\footnotetext{
Acknowledgements. The authors are grateful to all the mothers who took part and to the midwives for their cooperation and help in recruitment. The whole Avon Longitudinal Study of Parents and Children study team comprises interviewers, computer technicians, laboratory technicians, clerical workers, research scientists, volunteers and managers who continue to make the study possible. The Avon Longitudinal Study of Parents and Children study is part of the World Health Organization initiated European Longitudinal Study of Parents and Children. The authors thank C. Cooke, M. Martinez and F. Keenan for producing the elemental analysis data and I. Rogers who analysed data on maternal selenium intake in pregnancy.
}

\section{References}

1. Schwartz J, Gold D, Dockery DW, Weiss ST, Speizer FE. Predictors of asthma and persistent wheeze in a national sample of children in the United States. Association with 
social class, perinatal events, and race. Am Rev Respir Dis 1990; 142: 555-562.

2. Gold DR, Burge HA, Carey V, Milton DK, Platts-Mills T, Weiss ST. Predictors of repeated wheeze in the first year of life: the relative roles of cockroach, birth weight, acute lower respiratory illness, and maternal smoking. Am J Crit Med 1999; 160: 227-236.

3. Olesen AB, Ellingsen AR, Olesen H, Juul S, ThestrupPedersen K. Atopic dermatitis and birth factors: historical follow up by record linkage. BMJ 1997; 314: 1003-1008.

4. Gregory A, Doull I, Pearce N, et al. The relationship between anthropometric measurements at birth: asthma and atopy in childhood. Clin Exp Allergy 1999; 29: 330-333.

5. Leadbetter P, Pearce N, Cheng S, et al. Relationship between fetal growth and the development of asthma and atopy in childhood. Thorax 1999; 54: 905-910.

6. Fergusson DM, Crane J, Beasley R, Horwood LJ. Perinatal factors and atopic disease in childhood. Clin Exp Allergy 1997; 27: 1394-1401.

7. Langley-Evans S. Fetal programming of immune function and respiratory disease. Clin Exp Allergy 1997; 27: 1377-1379.

8. Kim HY, Picciano MF, Wallig MA, Milner JA. The role of selenium nutrition in the development of neonatal rat lung. Pediatr Res 1991; 29: 440-445.

9. Klesges LM, Murray DM, Brown JE, Cliver SP, Goldenberg $\mathrm{RL}$. Relations of cigarette smoking and dietary antioxidants with placental calcification. Am J Epidemiol 1998; 147: 127135.

10. Oryszczyn MP, Annesi-Maesano I, Campagna D, Sahuquillo J, Huel G, Kauffmann F. Head circumference at birth and maternal factors related to cord blood total IgE. Clin Exp Allergy 1999; 29: 334-341.

11. Sprietsma JE. Modern diets and diseases: NO-zinc balance. Med Hypotheses 1999; 53: 6-16.

12. Heo Y, Parsons PJ, Lawrence DA. Lead differentially modifies cytokine production in vitro and in vivo. Toxicol App Pharma 1996; 138: 149-157.

13. Miller TE, Golemboski KA, Ha RS, Bunn T, Sanders FS, Dietert RR. Developmental exposure to lead causes persistent immunotoxicity in Fischer 344 rats. Toxicol Sci 1998; 42: 129-135.

14. Gambling L, Charania Z, Hannah L, Antipatis C, Lea RG, McArdle HJ. Effect of iron deficiency on placental cytokine expression and fetal growth in the pregnant rat. Biol Reprod 2002; 66: 516-523.

15. Britton J, Pavord I, Richards K, et al. Dietary magnesium, lung function, wheezing, and airway hyperreactivity in a random adult population sample. Lancet 1994; 344: 357-362.

16. Avon Longitudinal Study of Parents and Childern (ALSPAC). http://www.alspac.bris.ac.uk/; 2001. Date accessed: May 13, 2004. Date updated: May 21, 2004.

17. Golding J, Pembrey M, Jones R, ALSPAC Study Team. ALSPAC - The Avon Longitudinal Study of Parents and Children. I. Study Methodology. Paediatr Perinat Epidemiol 2001; 15: 74-87.

18. Sherriff A, Peters TJ, Henderson J, Strachan D, ALSPAC Study Team. Risk factor associations with wheezing patterns in children followed longitudinally from birth to $3 \frac{1}{2}$ years. Int $J$ Epidemiol 2001; 30: 1473-1484.

19. Williams HC, Burney PG, Hay RJ, et al. The U.K. Working Party's Diagnostic Criteria for Atopic Dermatitis. I. Derivation of a minimum set of discriminators for atopic dermatitis. Br J Dermatol 1994; 131: 383-396.

20. Shaheen SO, Newson RB, Sherriff A, et al. Paracetamol use in pregnancy and wheezing in early childhood. Thorax 2002; 57: $958-963$

21. McKeever TM, Lewis SA, Smith C, Hubbard R. The importance of prenatal exposures on the development of allergic disease: a birth cohort study using the west midlands general practice database. Am J Crit Med 2002; 166: $827-832$.

22. StataCorp. Stata Statistical Software: Release 7.0. College Station, TX.: Stata Corporation, 2001.

23. Benjamini Y, Drai D, Elmer G, Kafkafi N, Golani I. Controlling the false discovery rate in behavior genetics research. Behav Brain Res 2001; 125: 279-284.

24. Akagi H, Grandjean P, Takizawa Y, Weihe P. Methylmercury dose estimation from umbilical cord concentrations in patients with Minamata disease. Environ Res 1998; 77: 98-103.

25. Nishigaki S, Harada M. Methylmercury and selenium in umbilical cords of inhabitants of the Minamata area. Nature 1975; 258: 324-325.

26. Harding JE. The nutritional basis of the fetal origins of adult disease. Int J Epidemiol 2001; 30: 15-23.

27. Zhang Z-W, Shimbo S, Miyake K, et al. Estimates of mineral intakes using food composition tables vs measures by inductively-coupled plasma mass spectrometry: Part 1. calcium, phosphorus and iron. Eur J Clin Nutrition 1999; 53: $226-232$

28. Levander OA. The need for measures of selenium status J Am Coll Toxicol 1986; 5: 37-44.

29. Paeratakul S, Popkin BM, Kohlmeier L, Hertz-Picciotto I, Guo X, Edwards LJ. Measurement error in dietary data: implications for the epidemiologic study of the diet-disease relationship. Eur J Clin Nutr 1998; 52: 722-727.

30. Myers GJ, Davidson PW, Cox C, et al. Prenatal methylmercury exposure from ocean fish consumption in the Seychelles child development study. Lancet 2003; 361: 1686-1692.

31. Prescott SL, Macaubas C, Smallacombe T, Holt BJ, Sly PD, Holt PG. Development of allergen-specific T-cell memory in atopic and normal children. Lancet 1999; 353: 196-200.

32. Martinez FD, Wright AL, Taussig LM, Holberg CJ, Halonen M, Morgan WJ. Asthma and wheezing in the first six years of life. The Group Health Medical Associates. $N$ Engl J Med 1995; 332: 133-138.

33. Wegmann TG, Lin H, Guilbert L, Mosmann TR. Bidirectional cytokine interactions in the maternal-fetal relationship: is successful pregnancy a TH2 phenomenon? Immunol Today 1993; 14: 353-356.

34. Thibault H, Galan P, Selz F, et al. The immune response in iron-deficient young children: effect of iron supplementation on cell-mediated immunity. Eur J Pediatr 1993; 152: 120-124.

35. Jason J, Archibald LK, Nwanyanwu OC, et al. The effects of iron deficiency on lymphocyte cytokine production and activation: Preservation of hepatic iron but not at all cost. Clin Exper Immuol 2001; 126: 466-473.

36. Kugelmas M, Carey WD, McClain CJ. Serum cytokine response to iron reduction in chronic hepatitis $\mathrm{C}$ patients. J Trace Elem Experi Med 2000; 13: 327-331.

37. Weiss G. Iron and immunity: a double-edged sword. Eur J Clin Invest 2002; 32: Suppl. 1, 70-78.

38. Brock JH, Mulero V. Cellular and molecular aspects of iron and immune function. Proc Nutr Soc 2000; 59: 537-540.

39. Rayman MP. Dietary selenium: time to act. BMJ 1997; 314 : 387-388.

40. Mathews F, Neil HAW. Nutrient intake during pregnancy in a cohort of nulliparous women. J Human Nutrition and Dietetics 1998; 11: 151-161.

41. Rogers I, Emmett P. Diet during pregnancy in a population of pregnant women in South West England. ALSPAC Study Team. Avon Longitudinal Study of Pregnancy and Childhood. Eur J Clin Nutr 1998; 52: 246-250. 